
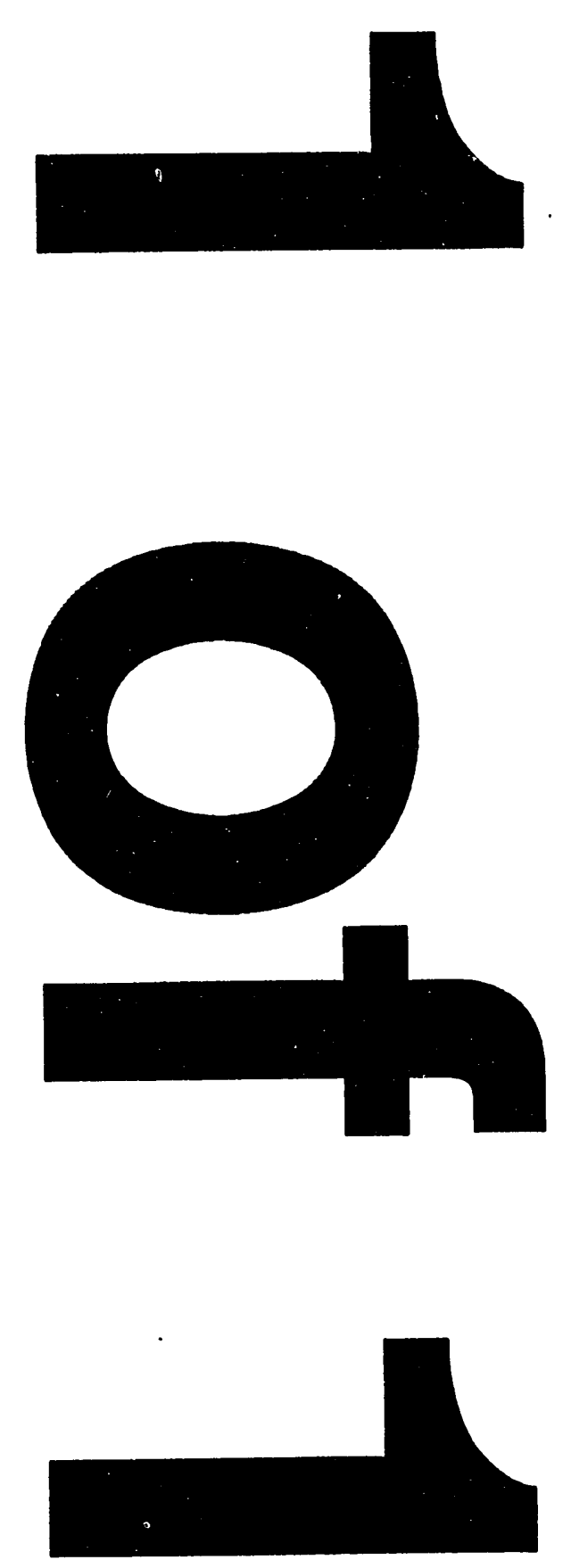
$\frac{2}{7-17}-93750$

UCRL-ID-115480

\title{
Scaling 2XIIB Impurity Radiation to BPNS
}

\author{
A. W. Molvik
}

November 9, 1993

This is an informal report intended primarily for internal or limited external distribution. The opinions and conclusions stated are those of the author and may or may not be those of the Laboratory.

Work performed under the auspices of the U.S. Department of Energy by the Lawrence Livermore National Laboratory under Contract W-7405-Eng-48. 


\section{DISCLAIMER}

This document was prepared as an account of work sponsored by an agency of the Uinited States Government. Neither the United States Government nor the University of California nor any of their employees, makes any warranty, express or implied, or assumes any legal liability or responsibility for the accuracy, completeness, or usefulness of any information, apparatus, product, or process disclosed, or represents that its use would not infringe privately owned rights. Reference herein to any specific commercial products, process, or service by trade name, trademark, manufacturer, or otherwise, does not necessarily constitute or imply its endorsemenh, recommendation, or favoring by the United States Government or the University of California. The views and opinions of authors expressed herein do not necesarily state or reflect those of the United States Government or the University of California, and shall not be used for advertising or product endorsenent purposes.

This report has been reproduced directly from the best available copy.

Available to DOE and DOE contractors from the Ofice of Scientific and Technical Information

P.O. Box 62, O2k Ridge, TN 37831

Prices available from (615) 576-8401, FTS 626-8401

Available to the public from the National Technical Information Service

US. Department of Commerce 5285 Port Royal Rd.

Springfield, VA 22161 
December 3, 1993

\title{
Scaling 2XIIB Impurity Radiation to BPNS
}

\author{
Arthur W. Molvik \\ Lawrence Livermore National Laboratory \\ University of California \\ Livermore, California 94550
}

\section{Introduction}

We compute the oxygen impurity radiation to be expected from the BPNS, Beam-Plasma Neutron Source, 1 and find that it should account for only $2 \%$ of the neutral-beam injected powei. The source of the oxygen is assumed to be the neutral beams, which include about $0.1 \%$ oxygen impurity in 2-5 s long pulse deuterium or hydrogen beams. 2

We compare these predictions with measurements of $\sim 10 \mathrm{~W} / \mathrm{cm}^{3}$ oxygen radiation from $2 \mathrm{XIIB}, 3$ operating in the range of $\mathrm{T}_{e}=40-120$ $\mathrm{eV}$. Oxygen was found to be injected by the neutral beams and was the principal impurity in 2XIIB. Somewhat surprisingly, the predicted radiated power density increases only a factor of 2 in the BPNS, reaching $15 \mathrm{~W} / \mathrm{cm}^{3}$, despite the density increasing by $1-2$ orders of magnitude. This prediction of relatively low radiated power in the BPNS is a result of primarily two effects:

(1) The ratio of the ionization rate to the charge-exchange recombination rate increases nearly proportionally as the plasma density since the beam currents are similar. This results in the BPNS being dominated by $\mathrm{O}+6$ with some $\mathrm{O}+7$ which radiate two orders of magnitude less power 4 than the $\mathrm{O}^{+4}$ and $\mathrm{O}^{+5}$. that dominated 2XIIB. 5

(2) The fraction of oxygen in the beams decreases from $2 \%$ in the 2XIIB 10 ms duration beams 3 to $0.4 \% 6$ or $1-2 \% 7$ in $0.5 \mathrm{~s}$ beams to $0.1-0.2 \%$ (which is near the OMA, Optical Multichannel Analyzer, diagnostic noise level) in 2-5 s long-pulse beams, ${ }^{2}$ and presumably to even lower levels in steady-state beams.

The BPNS 1 is a relatively low cost, plasma-based, $14 \mathrm{MeV}$ D-T neutron source for accelerated end-of-life testing of fusion reactor materials, Fig. 1. An intense flux (up to $5 \times 10^{18} \mathrm{n} / \mathrm{m}^{2} \cdot \mathrm{s}$ 
corresponding to $10 \mathrm{MW} / \mathrm{m}^{2}$ ) of $14-\mathrm{MeV}$ neutrons is produced in a fully-ionized high-density tritium target $\left(\mathrm{n}_{\mathrm{e}}=3 \times 10^{21} \mathrm{~m}^{-3}\right)$ by injecting a current of $120 \mathrm{keV} 8$ to $150-\mathrm{keV}^{1}$ deuterium atoms. The BPNS provides an 8-liter sample volume in which the $14.1 \mathrm{MeV}$ neutron flux exceeds $2 \mathrm{MW} / \mathrm{m}^{2}$, which is adequate for tests of welds and reactor submodules, 9,10 in addition to the basic materials tests for which the BPNS was optimized.

As with other beam-target neutron sources, 11 the heat deposited by the beam must be removed. The tritium plasma target and the energetic $\mathrm{D}^{+}$density prcduced by $\mathrm{D}^{0}$ injection are confined in a column of diameter $\leq 0.16 \mathrm{~m}$ by a linear magnet set, which provides magnetic fields up to $12 \mathrm{~T}$. Energy deposited by transverse injection of neutral beams at the midpoint of the column is removed by thermal conduction along the plasma column to the end regions. Longitudinal plasma pressure in the column is balanced by neutral gas pressure in the end tanks. The target plasma temperature is about $200 \mathrm{eV}$ at the beam-injection position and falls to $5 \mathrm{eV}$ or less in the end region. Ions reach the walls with energies below the sputtering threshold, and the wall temperature is maintained below $740 \mathrm{~K}$ by conventional cooling technology.

Although preliminary materials development is proceeding using fission neutron and low-level D-T neutron sources, final selection of materials, acquisition of engineering data, and qualification of fusion reactor materials require life tests in a facility that provides the appropriate D-T neutron spectrum. $9,10,12,13,14$ A plasma-based D-T fusion source would minimize questions of extrapolation, of displacement damage, energy of primary-knock-on atoms and the transmutation rates, because of differences in the neutron energy spectrum. 13 The development of low activation materials, 14 places stringent requirements on the absence of neutrons with energies exceeding $14.1 \mathrm{MeV} .12$ A steady-state neutron source avoids questions of rate-dependent phenomena that arise with low-dutycycle pulsed sources. 13 Although the actual reactor environment can be realized only in a specific reactor, a fusion-based neutron source can give valuable design information on synergistic effects in this complex environment. 


\section{Impurity Radiation Rates}

Our procedure in this report is to calculate the impurity radiation for $2 \mathrm{XIBB}^{3}$ using Ref. 4 , show that the result is close to that measured by Drake, then calculate the ionization states and expected radiated power for the BPNS from Ref. 4.

The ionization states in 2XIIB were set by competition between electron impact ionization and charge-exchange recombination on the neutral beams. The time scales for these are given in Table 1, which is adapted from Ref. 5. From comparing these time scales, it is apparent that $\mathrm{O} V$ and $\mathrm{O}$ VI should have been the dominant ionization states of oxygen in 2XIIB, as they were observed to be.

Table 1. Impurity time scales in 2XIIB

\begin{tabular}{|c|c|c|c|c|c|}
\hline $\begin{array}{l}\text { Ionization } \\
\text { state }\end{array}$ & O III & O IV & $\mathrm{OV}$ & $\mathrm{OVI}$ & O VII \\
\hline$\tau_{\text {ionize }}(\mu \mathrm{s})$ & 2.4 & 6.4 & 22 & 77 & $3.3 \times 10^{5}$ \\
\hline$\tau_{C X}(\mu s)$ & 910 & 33 & 40 & 50 & 63 \\
\hline
\end{tabular}

To estimate the radiation, we use an effective electron temperature that would produce the observed ionization states of 2 XIIB without charge-exchange recombination. Fig. 2, from Hulse, et al, 15 plots the average charge state $\langle Z\rangle$ VS $\mathrm{T}_{\mathrm{e}}$ for various ratios of neutral to electron density. Using the $\mathrm{n}_{\mathrm{n}} / \mathrm{n}_{\mathrm{e}}=0$ line, 2 XIIB data with $\mathrm{O} V$ dominating would correspond to $\mathrm{T}_{\mathrm{e}}=20-25 \mathrm{eV}$. In Fig. 3, from Jensen, et al., 4 we see that $20 \mathrm{eV}$ corresponds to the peak radiation power of $0.8 \times 10^{-}$ $25 \mathrm{~W}-\mathrm{cm}^{3}$. The neutral density in 2 XIIB corresponds to $\mathrm{n}_{\mathrm{n}} / \mathrm{n}_{\mathrm{e}}=10^{-3}$ which is beyond the range computed by Hulse, et al. in Fig. 2 .

Table 2 lists the electron impact ionization rates from Lotz, 16 and the charge exchange recombination times obtained for $150 \mathrm{keV}$ deuterium atoms incident on multiply charged oxygen, with the cross-sections from Meyer, et al.17 parameters for the BPNS are taken from Ref. 1 and are compared with those of 2 XIIB in Table 3. For $\tau_{C X}=1 /\left(\mathrm{nD}^{0} \sigma_{\mathrm{CX}} \mathrm{VD}^{0}\right), \mathrm{nD}^{0}$ is reduced in the BPNS mainly by the increase in the deuterium beam velocity, $\mathrm{vD}^{0}$. The charge exchange cross section for $150 \mathrm{keV}$ deuterium atoms on multiply- 
charged oxygen are approximately a factor of 5 smaller than with the $18 \mathrm{keV}$ deuterium beams of 2 XIIB. 17,18 From comparing the bottom 2 rows of Table 2 , we conclude that oxygen will ionize to at least $O$ VII in the BPNS. The neutral density in the beam injected cell corresponds to $n_{n} / n_{e}=10^{-5}$ in Fig. 2 , which is consistent with this conclusion.

Table 2. Impurity time scales in BPNS

\begin{tabular}{|c|c|c|c|c|c|}
\hline $\begin{array}{l}\text { Ionization } \\
\text { state }\end{array}$ & O IV & $\mathrm{OV}$ & $\mathrm{OVI}$ & O VII & O VIII \\
\hline $\begin{array}{c}\text { Ionization } \\
\text { potential }\end{array}$ & 77 & 114 & 138 & 739 & 871 \\
\hline $\begin{array}{l}<\sigma v> \\
200 \mathrm{eV} \\
\mathrm{e}^{-} \text {impact }\end{array}$ & $5.1 \times 10^{-9}$ & $1.8 \times 10^{-9}$ & $\begin{array}{l}5.91 \times \\
10^{-10}\end{array}$ & $\begin{array}{l}3.15 \times \\
10^{-12}\end{array}$ & $\begin{array}{l}6.0 \times \\
10^{-13}\end{array}$ \\
\hline$\tau_{\text {ionize }(\mu s)}$ & 0.061 & 0.17 & 0.53 & 99 & 520 \\
\hline$\tau_{C X X}(\mu s)$ & 500 & 300 & 200 & 140 & 80 \\
\hline
\end{tabular}


Table 3. Parameters of 2XIIB and BPNS

\begin{tabular}{|c|c|c|c|}
\hline Parameter & Symbol & $2 \mathrm{XIIB} 5$ & BPNS1 \\
\hline Density & $n_{e}\left(m^{-3}\right)$ & $5 \times 10^{19}$ & $3.2 \times 10^{21}$ \\
\hline Electron Temp. & $\mathrm{Te}(\mathrm{eV})$ & 100 & 200 \\
\hline Deuterium ion density & $\mathrm{nD}^{+}\left(\mathrm{m}^{-3}\right)$ & $4.3 \times 10^{19}$ & $8 \times 10^{20}$ \\
\hline $\begin{array}{l}\text { Deuterium ion average } \\
\text { energy }\end{array}$ & $\mathrm{E}_{\mathbf{i}}(\mathrm{keV})$ & 12 & 50 \\
\hline Oxygen ion density & no $\left(m^{-3}\right)$ & $1.5 \times 10^{18}$ & \\
\hline Oxygen charge state & $\left\langle Z_{\rangle}\right.$ & 4.5 & 6 \\
\hline Magnetic Field & B(Tesla) & 0.5 & 4 \\
\hline Neutral beam energy & $\mathrm{ED}^{0}(\mathrm{keV})$ & 18 & 150 \\
\hline Neutral beam current & $\mathrm{ID}^{0}(\mathrm{~A})$ & 500 & 400 \\
\hline $\begin{array}{l}\text { Beam density averaged } \\
\text { over plasma }\end{array}$ & $n D^{0}\left(m^{-3}\right)$ & $4 \times 10^{16}$ & $1.3 \times 10^{16}$ \\
\hline Hot plasma full lengt & $\operatorname{lh}(\mathrm{m})$ & 0.35 & 0.3 \\
\hline Plasma radius & $r_{p}(m)$ & 0.07 & 0.08 \\
\hline
\end{tabular}

We now need to estimate the impurity density to be able to obtain the impurity radiation. The impurity density will scale with the neutral beam impurity fraction and the impurity confinement relative to the energetic deuterium confinement. Drake measured about $2 \%$ oxygen impurity fraction in the 2XIIB $0.01 \mathrm{~s}$ neutral beams and determined that this was the primary source of the $3 \%$ oxygen impurity level in 2 XIIB. 3 TFTR $2 \mathrm{~s}$ neutral beams contain $0.1-0.2 \%$ of oxygen, near the noise level of the OMA diagnostic. 2 (This is determined from the low energy component of $\mathrm{H}$ or $\mathrm{D}$ resulting from the dissociation of accelerated water. Other impurities, that are not accompanied by hydrogen that radiates at the $\mathrm{H}_{\alpha}$ line, are not measured.) The oxygen impurity fraction is decreased by a factor of $10-20$ in going from $0.01 \mathrm{~s}$ to $2 \mathrm{~s}$ duration beams. We will use the $0.1 \%$ value, which should be conservative for steady-state beams.

Energetic impurity confinement, like deuteron confinement, is limited by electron drag. Energetic ions are magnetically trapped until they drag down to the ambipolar potential hole in energy space, then they are expelled out the ends. 
$\tau=\frac{\tau_{D}}{2} \ln \left(\frac{E_{D^{\circ}}}{Z \phi_{p}(R-1)}\right)$

where the drag time scales as

$\tau_{D} \propto \frac{A T_{e}^{15}}{Z^{2} n_{e} \ln \Lambda}$

Comparing the confinement times for $\mathrm{O}^{+6}$ and deuterium, only the $A$, $\mathrm{Z}$ and $\mathrm{EO}^{+6}=(16 / 18) \mathrm{ED}$ factors vary. In $2 \mathrm{XIIB}$ with $\mathrm{Z}=4$, the drag time for $\mathrm{O}^{+4}$ is $1 / 2$ that for a deuteron. The ratio of the confinement time of $\mathrm{O}^{+4}$ to a deuteron is then about 0.3 . In the BPNS with $\mathrm{Z}=6$, the ratio of the drag times decreases to 0.22 , and the ratio of the confinement times ranges between 0.12 and 0.18 depending on the plasma potential. A plasma potential drop of $5 \mathrm{~T} e$ between the hot plasma and the mirror results in $0^{+6}$ confinement 0.12 of that for a deuteron; whereas a near zero potential drop of $0.01 \mathrm{Te}$ gives a confinement ratio of 0.18 . We will use the value 0.18 as more appropriate to the BPNS which has a dense warm plasma to reduce potential differences along the plasma column. We then conclude that the higher charge state in the BPNS will reduce the impurity confinement relative to deuteron confinement by a factor of about 2.6 relative to $2 \mathrm{XIIB}$. We will ignore this factor, and use unity to be conservative.

We now estimate the impurity radiation power density from 2 XIIB (to compare with Drake's measurements) and from the BPNS. Fig. 3 (Fig. 1 from Jensen, et al. Ref. 4) shows the radiated power vs Te. The 2XIIB parameters are listed in Table 3 (Data from Table 6 of Ref. 5).

$\frac{P_{\text {Rad }}}{\operatorname{Vol}}\left(\frac{\text { Watts }}{\mathrm{cm}^{3}}\right)=\frac{n_{z}}{n_{e}} \cdot\left(n_{e}\right)^{2} \cdot \frac{P}{n_{e} n_{2}}$

For 3\% oxygen plasma density, as found by Drake 3 , we have $\mathrm{P} / \mathrm{V}=$ $(0.03)\left(5 \times 10^{13}\right)^{2}\left(10^{25}\right)=7.5 \mathrm{~W} / \mathrm{cm}^{3}$ which agrees with his result.

We now estimate the impurity radiation power density from the BPNS from Fig. 3. The effective temperature will be near the $100 \mathrm{eV}$ level, if $\mathrm{O}^{+6}$ dominates due to charge-exchange recombination (See $\mathrm{n}_{\mathrm{r}} / \mathrm{n}_{\mathrm{e}}=10^{-5}$ in Fig. 2), and the $200 \mathrm{eV}$ level which should apply in the plasma column where charge-exchange recombination will be 
negligible (See $n_{n} / n_{e}=0$ in Fig. 2). To be conservative, we take the peak at $200 \mathrm{eV}$ of about $1.5 \times 10^{-27} \mathrm{~W}-\mathrm{cm}^{3}$, recognizing that the real value could be a factor of 4 lower in the beam-injected cell. Then we have $P=(0.001)\left(3.2 \times 10^{15}\right) 2\left(1.5 \times 10^{-27}\right)=15 \mathrm{~W} / \mathrm{cm}^{3}$.

The radiated power from the 6 liter hot plasma volume is then in the range of 9 to $92 \mathrm{~kW}$. The higher value ignores the factors of 2.6 and 4 that should lower the oxygen density and radiation. Samples at a $10 \mathrm{~cm}$ radius will have a radiative power loading of 50 to 500 $\mathrm{kW} / \mathrm{m}^{2}$, which is quite tolerable. The plasma column will also radiate at a comparable level (Here, since charge-exchange recombination will be negligible outside of the hot plasma, the $200 \mathrm{eV}$ values from Fig. 3, as used above, should be appropriate.). The column volume will be equal to the 6 liter volume of the hot plasma, times the ratio of the lengths $(10 \mathrm{~m} / 0.3 \mathrm{~m})$ divided by the mirror ratio of 3 , yielding 67 liters. The total radiated power will then be $1.1 \mathrm{MW}$ or $2 \%$ of the incident $60 \mathrm{MW}$ power. If the oxygen impurity constitutes less than $0.1 \%$ of the neutral beam current as is likely, then the radiated powers given above will scale downwards proportionally.

This calculation neglects the power radiated at the ends of the column, where the volume increases rapidly and the temperature decreases towards zero. A high radiated power here is a desirable effect that helps to spread the heat load more evenly over the end cell and has little effect on the electron power balance (which is limited by Spitzer thermal conduction along the long column).

As an aside, it is interesting to compute the number of monolayers of water removed from the ion-source walls to produce the observed impurity fractions. 2XIIB sources extracted up to 80A for $0.01 \mathrm{~s}$ with $2 \%$ oxygen. With an ion source wall area of about $1600 \mathrm{~cm}^{2}$, this corresponds to 0.1-0.2 monolayers of water. TFTR sources extract 50 A for $2 s$ with $0.1-0.2 \%$ oxygen, and an ion source wall area of 6800 $\mathrm{cm}^{2}$, corresponding to $0.2-0.4$ monolayers of water. The similarity in these numbers may tell us something about source conditioning requirements, or may be pure coincidence. In any case, a steadystate source should remove adsorbed gas layers from the walls rather quickly; within minutes to hours, the impurity content of the beams should be $<<0.1 \%$. 


\section{Acknowledgments}

We thank Rob Goldston for raising the issue of impurity radiation from the BPNS, based on the relatively high radiation power density observed in $2 \mathrm{XIIB}$. This work was performed by LLNL for DOE under contract W-7405-ENG-48.

\section{References}

1. F. H. Coensgen, T. A. Casper, D. L. Correll, C. C. Damm, A. H. Futch, B. G. Logan, A. W. Molvik, and C. E. Walter, Journal of Fusion Energy 8,237 (1989); and F. H. Coensgen, T. A. Casper, D. L. Correll, C. C. Damm, A. H. Futch, B. G. Logan, and A. W. Molvik, Nuclear Science and Engineering 106, 138 (1990).

2. L. Grisham, PPPL, private communication (1/25/93). M. C. Vella, LBL, and J. Kim, GA, quote similar values.

3. Drake and Moos, Nuc. Fusion 20, 599 (1980), p. 609, and Drake and Moos, Nuc. Fusion 19, 407 (1979).

4. R. V. Jensen, D. E. Post, W. H. Grasberger, C. B. Tarter, and W. A. Lokke, Nuc. Fusion 17, 1187 (1977).

5. R. P. Drake, "Extreme ultraviolet diagnosis of a neutral-beamheated mirror machine, UCRL-52751, 1980.

6. W. G. Lahiak and J. S. Sullivan, "Test and Conditioning of an $80 \mathrm{kV}$, 0.5-second Industrially Fabricated Ion Source for Mirror Fusion Test Facility," Proc. 11th Symposium on Engineering Problems of Fusion Research, Vol. 1,166 (1985).

7. J. Kim, A. P. Colleraine, J. A. Fasolo, et al., "Operating Experience with $80-\mathrm{keV} / 80-\mathrm{A}$ Ion Sources in use for Doublet III NBI Experiments," Proc. 10th Symposium on Engineering Problems of Fusion Research, Vol. 2,1446 (1983).

8. E. B. Hooper, UCRL-ID-115481 (Nov. 9,1993).

9. M. Abdou, et al, "FINESSE: A Study of the Issues, Experiments and Facilities for Fusion Nuclear Technology Research and Development, Interim Report, Univ. of Calif., Los Angeles PPG-821, UCLA-ENG-8430 (1984). 
10. M. Abdou, et al., "Modeling, Analysis and Experiments for Fusion Nuclear Technology," Fusion Engineering and Design 6, 3 (1988). Section 3

11. F. H. Coensgen, G. P. Lawrence, and S. Cierjacks, "Neutron Sources for Fusion Materials Testing," Nuclear Data for Science and

Technology, S. M. Qaim, ed. (Springer-Verlag Berlin Heidelberg 1992) p. 395.

12. S. Cierjacks and K. Ehrlich, "Nuclear Data for Fusion Materials Research," Nuclear Data for Science and Technology, S. M. Qaim, ed. (Springer-Verlag Berlin Heidelberg 1992) p. 259.

13. D. G. Doran and J. E. Leiss, "Neutron Source Evaluation Process and Evaluation Panel Report," Journal of Fusion Energy 8, 137 (1989).

14. R. W. Conn, E. E. Bloom, J. W. Davis, et al, "Lower Activation Materials and Magnetic Fusion Reactors," Nuclear Technology/Fusion 5, 291 (1984).

15. R. A. Hulse, D. E. Post, and D. R. Mikkelsen, J. Phys. B: Atom. Molec. Phys. 13, 3895 (1980).

16. Wolfgang Lotz, Astroph. J., Suppl. 128, 14, 207 (1967).

17. R. W. Meyer, R. A Phaneuf, H. J. Kim, P. Hvelplund, and P. H. Stelson, Phys. Rev. A 19, 515 (1979).

18. D. H. Crandall, R. A Phaneuf, and F. W. Meyer, Phys. Rev. A 19, 504 (1979). 


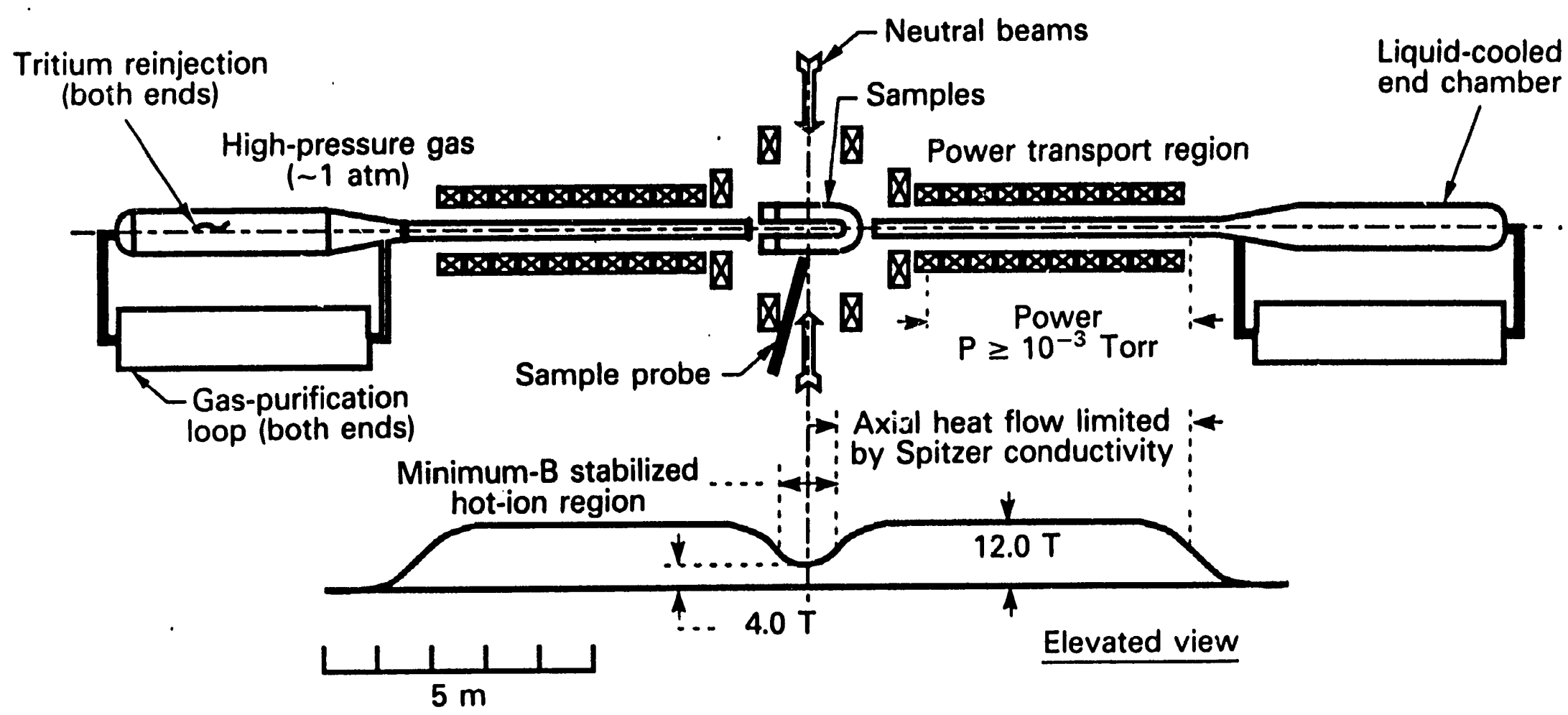

Fig. 1. Schematic of beam-plasma neutron source. The central section of the vacuum chamber and the neutron shielding of superconducting magnets are not shown. 

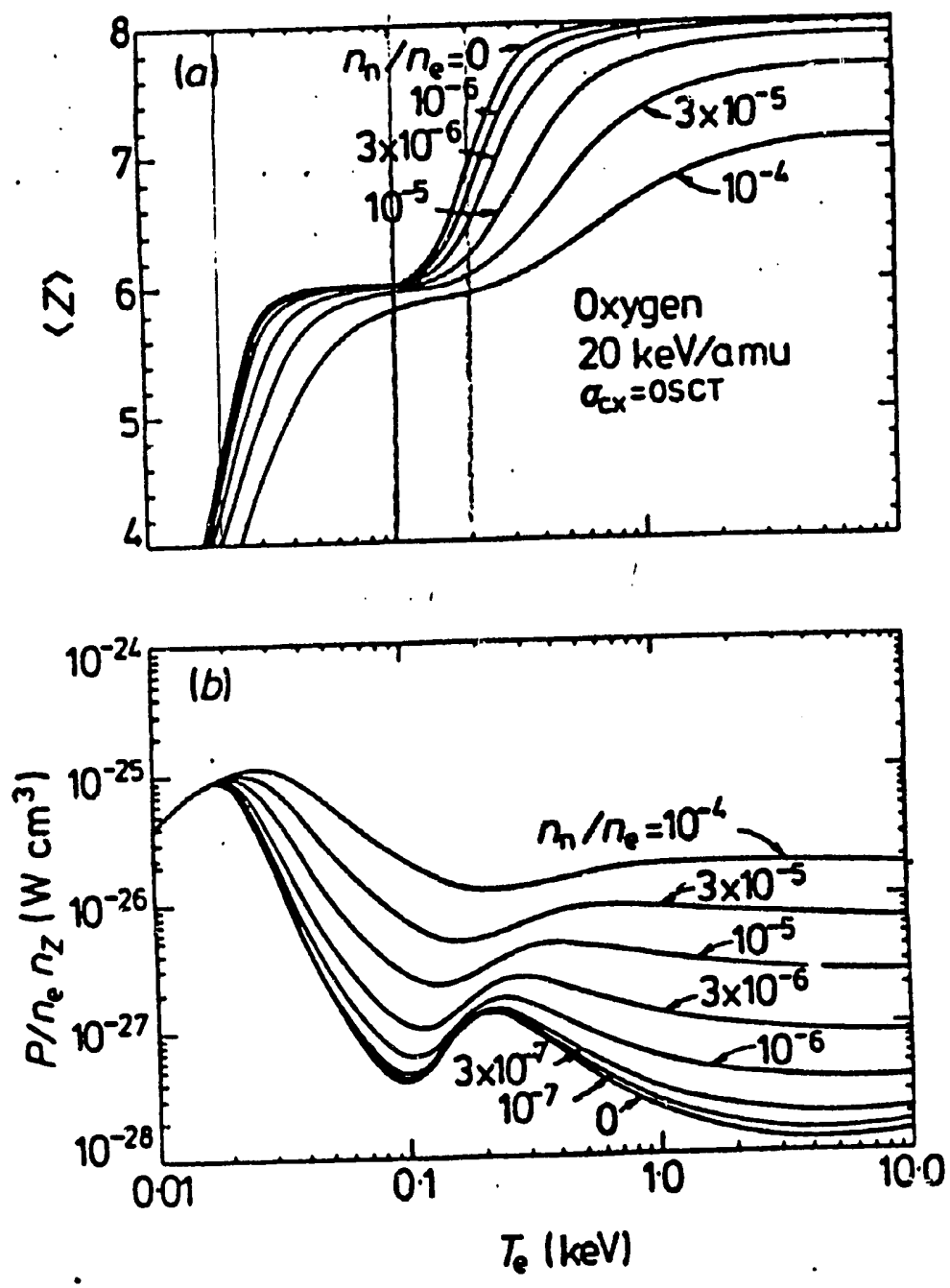

Fig. 2 Oxygen neutral beam modified 'coronal' equilibria. Hydrogen neutrals at $20 \mathrm{keV}$ amu ${ }^{-1}$ are considered, using the osCr cross sections. The curves are parameterised by the neutral fraction $n_{\mathrm{a}} / n_{\mathrm{o}}$. Shown are $(a)$ the average charge state $\langle Z\rangle_{\mathrm{b}}$ and $(b)$ the overall radiation rate coefficient $P / n_{\mathrm{e}} n_{\boldsymbol{x}}$ both as functions of the electron temperature. 


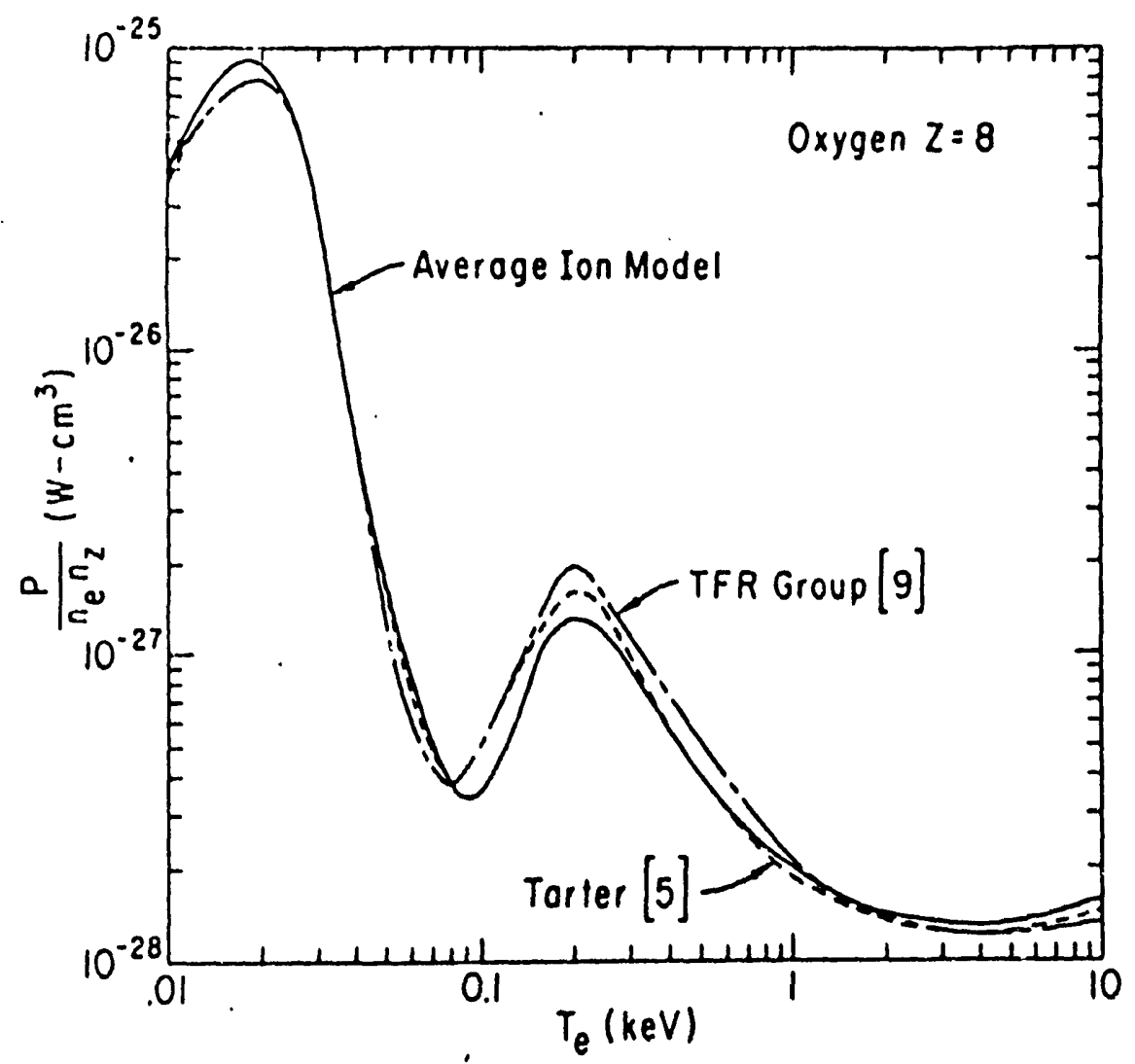

Fig. 3 Total radiated power as a function of electron temperature for oxygen. 



$1 / 24 / 94$
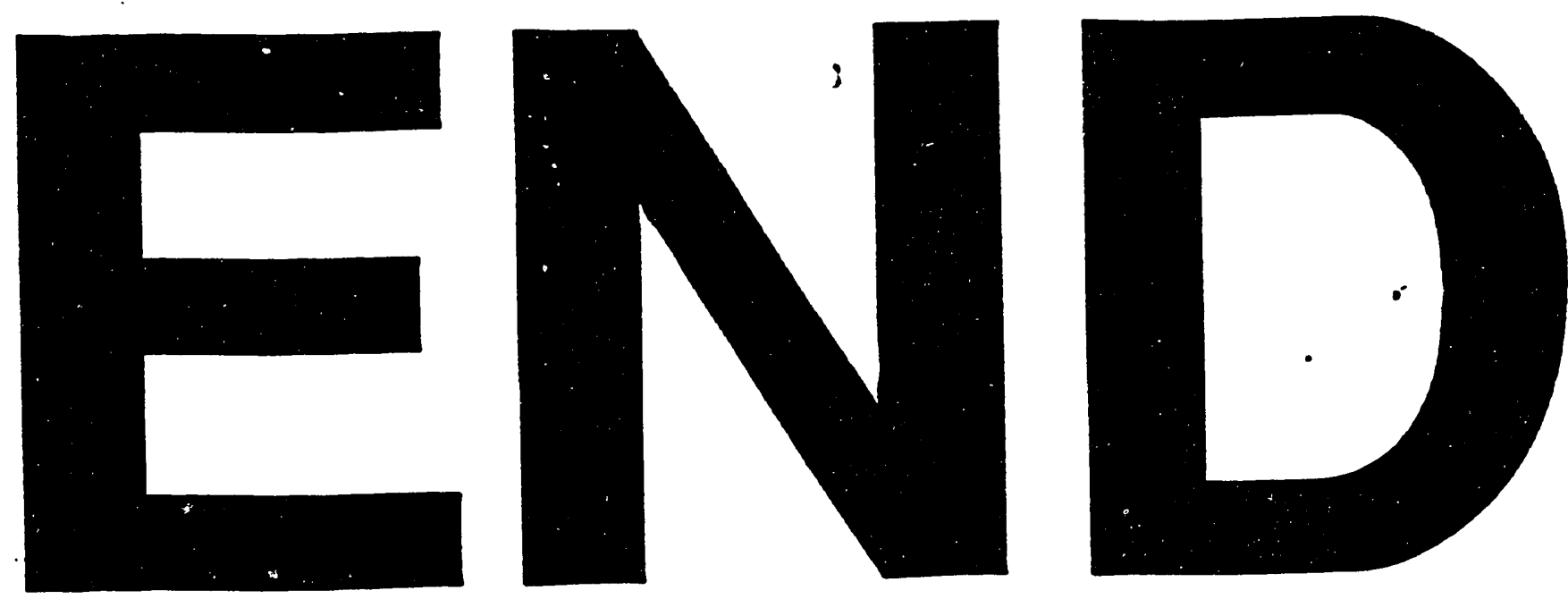